OPEN ACCESS

Edited by:

Cristina Maccalli,

Sidra Medicine, Qatar

Reviewed by:

Anna Karolina Kozlowska,

Poznan University of Medical

Sciences, Poland

Chiara Bonini,

Vita-Salute San Raffaele University,

Italy

*Correspondence: Jerome Ritz

jerome_ritz@dfci.harvard.edu

${ }^{\dagger}$ These authors share first authorship

Specialty section:

This article was submitted to

Cancer Immunity

and Immunotherapy,

a section of the journal

Frontiers in Immunology

Received: 20 September 2020 Accepted: 14 December 2020

Published: 15 February 2021

Citation:

Pinte L, Cunningham A, Trébéden-Negre H, Nikiforow $S$ and Ritz J (2021) Global Perspective on the Development of Genetically Modified Immune Cells for Cancer Therapy.

Front. Immunol. 11:608485. doi: 10.3389/fimmu.2020.608485

\section{Global Perspective on the Development of Genetically Modified Immune Cells for Cancer Therapy}

\author{
Laetitia Pinte $^{\dagger}$, Amy Cunningham ${ }^{\dagger}$, Helene Trébéden-Negre, Sarah Nikiforow \\ and Jerome Ritz*
}

Connell and O'Reilly Families Cell Manipulation Core Facility, Dana-Farber Cancer Institute, Harvard Medical School, Boston, MA, United States

Since the first genetically-engineered clinical trial was posted to clinicaltrials.gov in 2003 (NCT00019136), chimeric antigen receptor (CAR) and T-cell receptor (TCR) therapies have exhibited unprecedented growth. USA, China, and Europe have emerged as major sites of investigation as many new biotechnology and established pharmaceutical companies invest in this rapidly evolving field. Although initial studies focused primarily on CD19 as a target antigen, many novel targets are now being evaluated. Nextgeneration genetic constructs, starting materials, and manufacturing strategies are also being applied to enhance efficacy and safety and to treat solid tumors as well as hematologic malignancies. Fueled by dramatic clinical efficacy and recent regulatory approvals of CD19-targeted CAR cell therapies, the field of engineered cell therapeutics continues to expand. Here, we review all 745 genetically modified CAR and TCR clinical trials with anticipated accrual of over 28,000 patients posted to clinicaltrials.gov until $31^{\text {st }}$ of December 2019. We analyze projected patient enrollment, geographic distribution and phase of studies, target antigens and diseases, current strategies for optimizing efficacy and safety, and trials expected to yield important clinical data in the coming 6-12 months.

Keywords: chimeric antigen receptor T cells, $\mathrm{T}$ cell receptor, cell therapy, genetically modified cells, clinical trials

\section{INTRODUCTION}

Genetic engineering of immune cells to express defined antibody-based chimeric antigen receptors (CAR) has led to highly effective cell-based therapeutics for cancer. Several groundbreaking preclinical and clinical efforts in the late 1980's and 1990's laid the groundwork for modern CAR and TCR clinical investigation. These include clinical studies of ex vivo expanded tumor infiltrating lymphocytes (1) and the first chimeric receptors developed by Kurosawa, Eshhar, and colleagues (24). When combined with advances in viral transduction of immune cells (5-7) and the incorporation of costimulatory domains with receptor constructs $(8-10)$ these different streams of scientific discovery enabled the dramatic number of CAR and T cell receptor-based (TCR) therapies that are currently ongoing. This foundational work has been previously well-reviewed (11-13). Now, already in clinic for over a decade, anti-CD19 CAR-T cells have shown remission rates as high as $90 \%$ in pediatric ALL and $50 \%-90 \%$ in adult B-cell malignancies (14-16). Remarkable efficacy in patients with multiply relapsed or refractory disease led to approval of 
tisagenlecleucel and axicabtagene ciloleucel anti-CD19 CAR-T therapies for relapsed B cell leukemia and lymphoma, in the United States, Europe and Japan (17-20). In July 2020, the US FDA granted accelerated approval to brexucabtagene autoleucel for relapsed adult mantle cell lymphoma (21). Additional antiCD19 CAR-T constructs are in late stage development, and Phase III trials are now comparing CAR products with standard second-line therapies. The results of these studies may further extend the indications for anti-CD19 CAR-T therapy to patients prior to developing highly resistant tumor cells and complications from prior therapy.

The success of CAR-T therapies has sparked a worldwide surge of clinical trials seeking to improve safety and efficacy and identify new disease indications for genetically-engineered immune cell therapies. To quantitatively explore the evolution of this new treatment modality, we generated a database encompassing all CAR and TCR-based interventional clinical trials posted on clinicaltrials.gov from the first trial recorded in 2003 to the last one registered in 2019.

\section{METHODS}

Clinical trials involving TCR and CAR therapies were extracted from clinicaltrials.gov. Data were then sorted and analyzed manually for quality control purposes. Only interventional trials posted prior to December 31, 2019 were selected. Trials investigating lymphocyte-based therapies not featuring genetic modifications with CARs or TCRs, such as antigen-expanded cytotoxic T lymphocytes or tumor-infiltrating lymphocytes, were excluded from this report. Average patient numbers were rounded to the closest and smaller integer. Of note, reported patient enrollment indicates anticipated enrollment over the full course of each trial and does not reflect actual numbers of patients enrolled at any given time point. Country totals reflect the location of anticipated patient enrollment to the clinical trial and not the sponsor's country of origin. Clinical trial phases and sponsors were defined as described in Supplementary Tables 1 and 2. Trial status, e.g. active, recruiting, not yet recruiting, was not collected in this analysis. Clinicaltrials.gov data is limited by what end-users disclose in trial entries and not all trials are registered. If a parameter was omitted in a clinicaltrials.gov entry, the trial was excluded from reported totals for that variable, e.g. a CAR study with unspecified target was excluded from tables summarizing number of trials per target. Additional information regarding these trials may be publicly available but was not included in this analysis. Other databases such as EudraCT also catalogue clinical trials conducted with genetically modified immune cells. Since these databases largely overlap with clinicaltrials.gov, we limited our analysis to trials listed in clinicaltrials.gov.

\section{SEVENTEEN-YEAR HISTORY OF CLINICAL INVESTIGATION}

Since the first genetically-engineered T-cell trial was listed on clinicaltrials.gov in 2003, 745 total CAR and TCR clinical trials have been registered (Figure 1A). Between 2003 and 2007, only eight trials were listed. Studies increased in the next 5-year period 2008-2012, in which 72 new clinical trials were posted. Annual new trials rose dramatically beginning in 2014 (Figure 1A). In the most recent 5-year period, 608 new trials were registered on clinicaltrials.gov. Reported patient enrollment reflected trends observed in the number of new clinical trials (Figure 1B). (Of note, reported patient enrollment on clinicaltrials.gov may not reflect actual patient totals on trial). In the early period from 2003 to 2008, only 306 patients were anticipated to enroll in a limited number of clinical trials. From 2009 to 2014, expected eventual enrollment across all trials increased to 1,709 patients. This number rose dramatically in the last 5-year period in which 24,695 patients were anticipated in CAR and TCR trials.

\section{A}

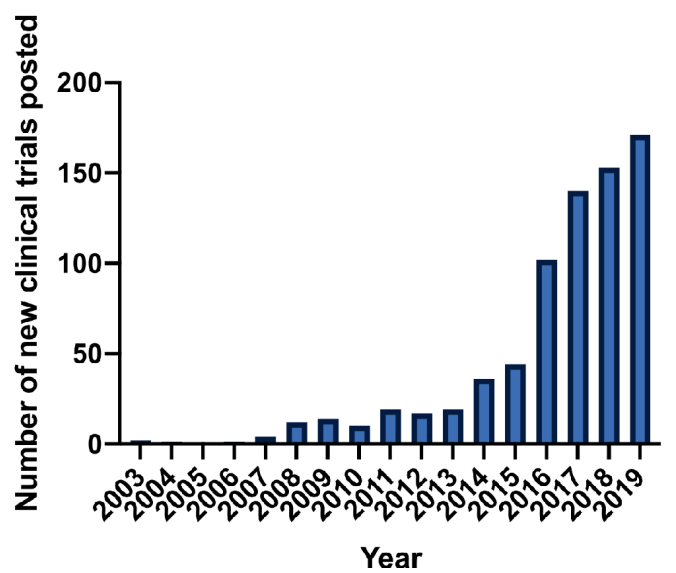

B

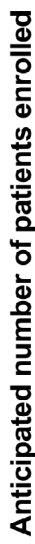

FIGURE 1 | CAR and TCR clinical trials on clinicaltrials.gov. (A) New clinical trials posted per year. (B) Anticipated patient enrollment per year. 
Overall, 641 CAR clinical trials were listed compared to 102 TCR-based therapies, while two trials involved dual CAR and TCR therapies. Although genetically-engineered TCR trials predominated from 2003 to 2008, the sharp increase in clinical investigation that began in 2014 focused on CAR trials (Figure 2A). This trend continued in 2019, when 158 new CAR trials were listed while only 11 new TCR trials were started.

\section{EVOLVING INTERNATIONAL LANDSCAPE OF GENETICALLY MODIFIED CELL THERAPIES}

To better understand where CAR and TCR trials have taken place, we analyzed clinical trial postings by geographic area. Forty-seven percent of overall trials were based in China, 44\% from USA, and 6\% European (Figure 2B). Other countries including Japan, Australia, Canada, Malaysia, New Zealand, and Israel hosted few trials ( $\mathrm{n}=14$, collectively). While most CAR trials opened in China ( $n=330$ of 641 ), overtaking USA in 2015, most TCR studies were conducted in the USA ( $n=69$ of 102).

From 2003 to 2007 only eight trials were listed in clinicaltrials.gov, four CAR trials and four TCR-based studies, all conducted in the USA. The first CAR trial began in the USA in 2003. Registered CAR studies opened in Europe in 2010, and China entered the field in 2012 (Figure 3A). From 2012 to 2015, China hosted 23 CAR trials. In 2016 alone, 61 CAR trials occurring in China were registered. Since 2016, more CAR trials have opened in China than in USA (307 vs. 159, respectively). During this same period, 31 new CAR trials began in Europe. Following this trend, trials in China reported the highest annual patient enrollment since 2016, followed by
USA and Europe (Figure 3B). Though most CAR clinical trials took place in China, average expected patient enrollment per trial was significantly lower than in USA trials ( $\mathrm{p}$-value = 0.0003 , Figure 3C). This difference was especially striking for late phase trials (phase II/III and III). USA opened five late phase trials with average anticipated enrollment of 208 patients, while China had five late phase trials, averaging 18 reported patients per trial.

From 2003 until 2013 academic sponsors supported the vast majority of trials (91\%). Subsequently, industry became more engaged in the field and commercial entities are now the predominant sponsors of both CAR and TCR-based clinical trials. In the last 5 years, $54 \%$ of studies had industry sponsors and $46 \%$ had academic sponsors. This trend is particularly evident in China, where 55 different companies funded CAR and TCR trials versus 34 in USA and 12 in Europe from 2003 to 2019. This may reflect differences in regulatory requirements between countries and Chinese initiatives such as "Made in China 2025" targeting investments in research and development $(22,23)$. Across all countries, industry sponsored nearly half of all CAR $(n=301)$ and TCR trials $(n=42)$ (Supplementary Table 2). International collaborations and mergers have supported the worldwide increase in geneticallymodified immune therapies, largely in CAR products. In 2017, Johnson \& Johnson invested \$350 million in the Chinese Biotech Nanjing Legend Biotechnology Co. for the global rights to codevelop and market experimental CAR treatments (24) and Novartis invested \$40 million into Cellular Biomedicine Group in USA (25). Major corporate buyouts of USA CAR manufacturers also occurred. Gilead bought Kite Pharma in August 2017 (26), and Celgene bought Juno Therapeutics in January 2018 (27). Bristol Myers Squibb then acquired Celgene in 2019 (28).
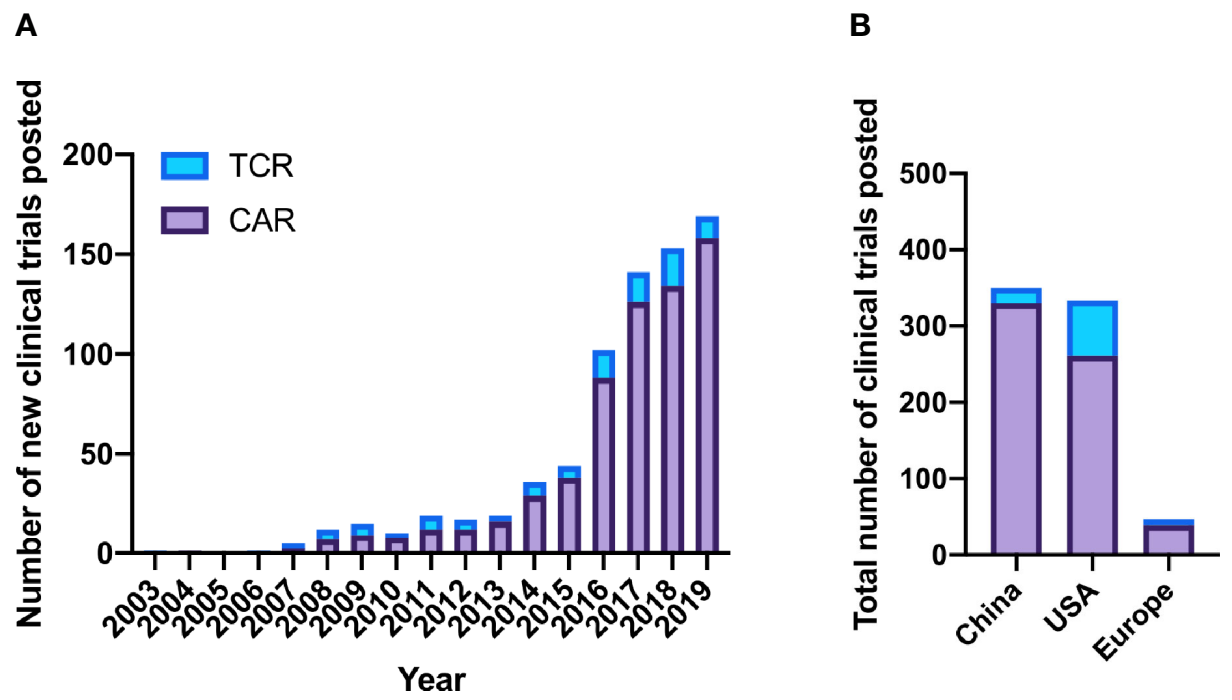

FIGURE 2 | CAR vs. TCR clinical trials posted on clinicaltrials.gov. (A) CAR and TCR clinical trials posted per year. (B) Total CAR and TCR trials by location 20032019. 

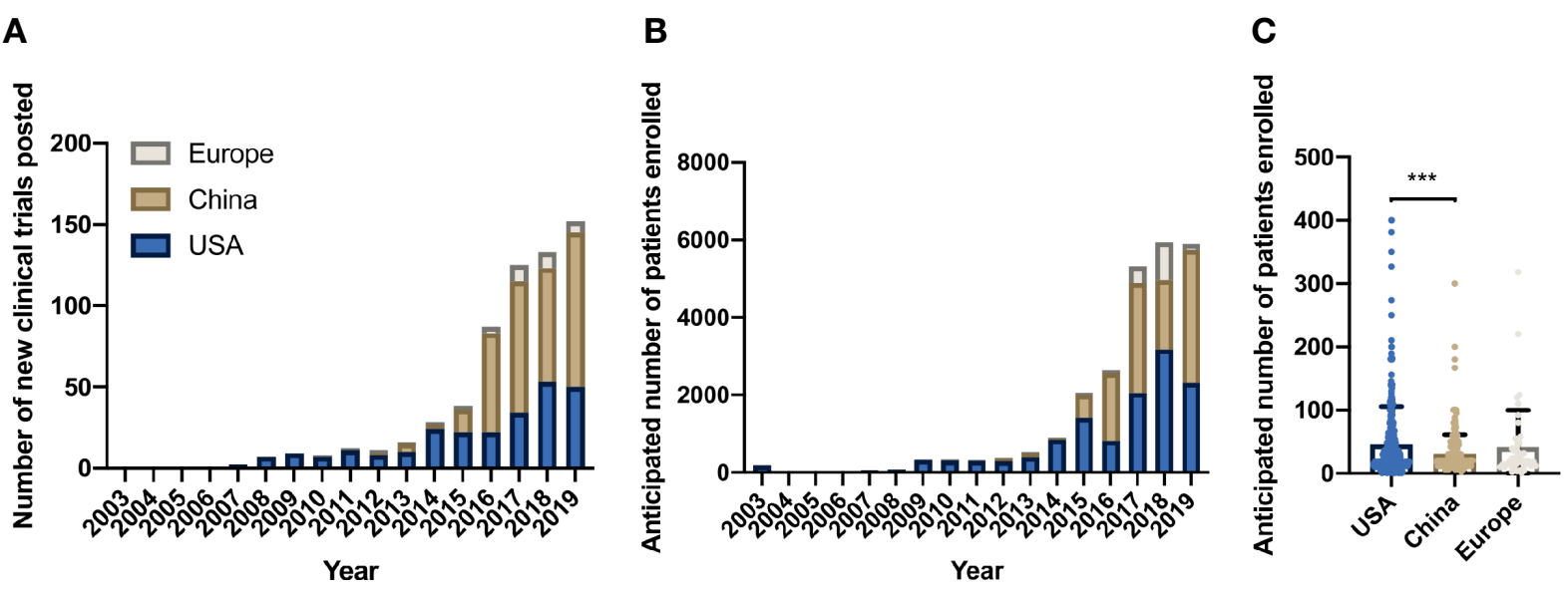

FIGURE 3 | Location of CAR trials on clinicaltrials.gov. (A) New CAR trials per year by location. (B) Anticipated patient enrollment in CAR trials per year by location. (C) Comparison of total anticipated patient enrollment by location 2003-2019 ( $p=0.0003$, one-way ANOVA test). ${ }^{* \star \star}$ denotes $p$-value $<10^{-3}$.

\section{MOST STUDIES CONTINUE TO BE EARLY-PHASE CLINICAL TRIALS}

CAR trials posted from 2003 to 2015 were all early-phase studies (phase I, I/II, or II), which focused on patients with relapsed/ refractory disease with few treatment options and did not include comparator cohorts. While the dramatic efficacy of anti-CD19 CAR-T cells demonstrated in phase II trials was sufficient for regulatory approval, randomized trials were initiated in 2018 to extend their clinical indications. Late phase studies were distributed across USA, China, and Europe $(n=5,5$, and 3, respectively). USA and Europe held the highest total anticipated patient enrollment in late phase trials ( $\mathrm{n}=1041,558$ respectively vs. 90 in China). The first randomized phase III trial opened in January 2018, a study of Kite's axicabtagene ciloleucel anti-CD19 CAR-T cells in adult relapsed/refractory diffuse large B cell lymphoma vs. standard of care second-line salvage chemotherapy plus autologous stem cell transplant (ASCT) (NCT03391466, Table 1). In 2018, Novartis initiated phase III randomized trials of tisagenlecleucel anti-CD19 CAR-T versus standard of care second-line therapies (such as blinatumomab or inotuzumab ozogamicin) in adult patients with relapsed/ refractory hematological malignancies (NCT03628053, NCT03570892). Celgene also launched phase III trials the same year to test its anti-CD19 CAR-T in Non-Hodgkin's Lymphoma (NCT03575351) and BCMA-CAR T in multiple myeloma, (NCT03651128) in comparison to standard therapies (salvage chemotherapy and ASCT or later-generation Imids/proteasome inhibitors and/or daratumumab, respectively). In 2019, Janssen initiated a phase III study of its anti-BCMA CAR-T vs. combination pomalidomide, bortezomib, dexamethasone or daratumumab, pomalidomide and dexamethasone in lenalidomide-refractory adult myeloma (NCT04181827). In July 2019, the first late phase trial involving CAR-T cells in solid tumors was listed, a phase IIb study of an anti-CEA CAR combined with either nanoparticle albumin-bound paclitaxel, 5-fluorouracil/folinic acid, or capecitabine vs. chemotherapy alone in CEA+ pancreatic adenocarcinoma liver metastases (NCT04037241). In contrast, all TCR trials continue to be early-phase, and none have demonstrated sufficient efficacy to garner fast-track approval to date. That the clear majority of clinical trials continue to be early phase studies indicates the field of genetically-engineered cellular therapeutics remains relatively young, with great emphasis on innovation and development of new cellular products. These products will require demonstration of safety and preliminary efficacy before they can expand to large multicenter trials that include comparisons with standard treatments.

Long-term clinical data is emerging for early anti-CD19 CAR-T constructs. Two-year follow-up of patients receiving axicabtagene ciloleucel in Zuma-1 (NCT02348216) indicates the drug can induce durable responses and median overall

TABLE 1 | CAR therapies compared to standard of care.

\begin{tabular}{lcccccc}
\hline NCT\# & Year posted & Phase & CAR-target & Company & Disease & Anticipated Patient Enrollment \\
\hline NCT03391466 & 2018 & 3 & CD19 & Gilead/Kite & DLBCL & ALL \\
NCT03628053 & 2018 & 3 & CD19 & Novartis & NHL & 220 \\
NCT03570892 & 2018 & 3 & CD19 & Novartis & NHL & 318 \\
NCT03575351 & 2018 & 3 & CD19 & Celgene & MM & 182 \\
NCT03651128 & 2018 & 3 & BCMA & Celgene & MM & 95 \\
NCT04181827 & 2019 & 3 & BCMA & Janssen & &
\end{tabular}


survival greater than 2 years with manageable long-term safety in adult large B-cell lymphoma (29). Follow-up studies of patients receiving commercial axicabtagene ciloleucel and tisagenlecleucel confirm the remarkable efficacy and manageable safety profiles of these drugs beyond the clinical trial setting (30-33). Though not yet commercially approved at the time of this review, long-term trial data from 269 adult B-cell lymphoma patients receiving lisocabtagene maraleucel, an antiCD19 CAR-T cell therapy, indicated 18.8 month median overall survival, $73 \%$ objective response rate, $53 \%$ complete response rate, and $12 \%$ occurrence of grade 3 or worse cytokine release syndrome or neurological events (NCT02631044) (34). However, across studies it appears there is still room for optimization of these therapies. Late phase randomized studies may help to refine treatment algorithms, perhaps allowing for patients to receive CAR therapies as earlier treatment options and further identifying prognostic indicators to help precisely identify patients who would most benefit from particular CAR therapies.

\section{CAR AND TCR TARGETS}

The first successful CAR-T cells targeted CD19 expressed on preB ALL, B-cell lymphomas, and normal B cells. Two-hundred fifty-five CAR clinical trials enrolling an anticipated 11,783 patients targeted CD19 (Table 2A). The next most frequent target in hematologic malignancies was BCMA in multiple myeloma, with 2,517 patients expected to enroll in 47 singleagent BCMA CAR trials. The clinical efficacy of BCMA CAR-T cells has been noted in several studies in relapsed/refractory myeloma, and FDA approval is expected for several such products in the near future (35-38). CD22 has emerged as a new CAR target in B-ALL and B-cell lymphoma $(n=15)$ and CD30 in relapsed Hodgkin's disease and T-cell lymphomas $(\mathrm{n}=15)$. Overall, CARs targeting 23 different surface antigens expressed by hematologic malignancies have been evaluated in clinical trials (Table 2A). Many of these antigens are expressed selectively by normal B cells and B-cell malignancies (ALL, CLL, B-cell lymphoma, myeloma). In these cases, successful therapy also results in the elimination of normal B cells or plasma cells, and patients are supported by administration of normal human gamma globulin until normal B cells recover sufficiently to produce endogenous antibodies. Several recent trials also target antigens expressed on T-cell or myeloid malignancies. In these cases, CARs may also target normal $\mathrm{T}$ cells or normal hematopoietic stem cells, potentially resulting in severe immune deficiency or life-threatening pancytopenia. In many of these trials, treatment is planned as a bridge to allogeneic stem cell transplantation. In other cases, innovative approaches are designed to mitigate these toxicities.

Although most single-target CARs were specific to antigens expressed primarily on hematopoietic malignancies $(n=390)$, many solid tumor CARs were also evaluated $(n=156$, Table 2B). The first solid tumor CAR trial was posted on
TABLE 2A | Single targets for CAR therapies in liquid tumor indications.

\begin{tabular}{lcc}
\hline Target & Number of clinical trials & Expected patient enrollment \\
\hline CD19 & 255 & 11783 \\
BCMA & 47 & 2517 \\
CD22 & 15 & 472 \\
CD30 & 15 & 391 \\
CD123 & 14 & 535 \\
CD20 & 11 & 378 \\
CD33 & 6 & 136 \\
CS1 & 3 & 102 \\
CD7 & 4 & 155 \\
NKG2DL & 4 & 194 \\
CD138 & 2 & 43 \\
CD4 & 2 & 72 \\
LeY & 2 & 51 \\
CD133 & 1 & 20 \\
CD37 & 1 & 34 \\
CD38 & 1 & 72 \\
CD44v6 & 1 & 10 \\
CD5 & 1 & 21 \\
FLT3 & 1 & 35 \\
KLC of Ig & 1 & 54 \\
PD-L1 & 1 & 20 \\
ROR & 1 & 0 \\
TRBC1 & 1 & 55 \\
\hline & & \\
\hline & & \\
\hline
\end{tabular}

TABLE 2B | Single targets for CAR therapies in solid tumor indications.

\begin{tabular}{|c|c|c|}
\hline Target & Number of clinical trials & Expected patient enrollment \\
\hline Mesothelin & 22 & 654 \\
\hline GD2 & 17 & 528 \\
\hline EGFR & 16 & 379 \\
\hline HER2 & 14 & 463 \\
\hline GPC3 & 13 & 330 \\
\hline CEA & 12 & 260 \\
\hline MUC1 & 9 & 399 \\
\hline PSMA & 7 & 140 \\
\hline EpCAM & 5 & 174 \\
\hline IL13R $\alpha 2$ & 5 & 201 \\
\hline NKG2DL & 5 & 144 \\
\hline CLD18 & 3 & 60 \\
\hline ROBO1 & 3 & 42 \\
\hline B7-H3 & 2 & 80 \\
\hline c-Met & 2 & 16 \\
\hline CD147 & 2 & 54 \\
\hline PD-L1 & 2 & 42 \\
\hline PSCA & 2 & 150 \\
\hline ROR & 2 & 148 \\
\hline AFP & 1 & 18 \\
\hline CD171 & 1 & 40 \\
\hline CD20 & 1 & 18 \\
\hline CD70 & 1 & 113 \\
\hline Chlorotoxin & 1 & 18 \\
\hline EphA2 & 1 & 60 \\
\hline FAP & 1 & 4 \\
\hline Folate receptor & 1 & 18 \\
\hline GP100 & 1 & 6 \\
\hline LeY & 1 & 82 \\
\hline LMP & 1 & 20 \\
\hline MUC16 & 1 & 30 \\
\hline VEGFR2 & 1 & 24 \\
\hline
\end{tabular}


TABLE 2C | CAR therapies targeting multiple antigens.

\begin{tabular}{lcc}
\hline Target & $\begin{array}{c}\text { Number of clinical } \\
\text { trials }\end{array}$ & $\begin{array}{c}\text { Expected patient } \\
\text { enrollment }\end{array}$ \\
\hline CD19/CD22 & 17 & 598 \\
CD19/CD20 & 13 & 275 \\
CD19/BCMA & 5 & 85 \\
BCMA/CS1 & 1 & 84 \\
BCMA/CD138 & 1 & 10 \\
BCMA/CD38 & 1 & 80 \\
CD20/CD22/CD10 & 1 & 30 \\
CD19/CD20/CD22/CD30 & 1 & 10 \\
CD20/CD3 & 1 & 12 \\
CD123/CLL1 & 1 & 20 \\
CD123/CD33 & 1 & 10 \\
CD33/CLL1 & 1 & 70 \\
C-MET/PDL1 & 1 & 50 \\
Mesothelin/CD19 & 1 & 4 \\
Muc1/CLL1/CD33/CD38/ & 1 & 10 \\
CD56/CD123 & & \\
Nectin4/FAP & 1 & 10 \\
PD-L1/CD80/CD86 & 1 & \\
\hline
\end{tabular}

clinicaltrials.gov in 2003 and utilized anti-L1-CAM (CD171) CAR CD8+T cells to treat patients with neuroblastoma (NCT00006480) (39). Other early solid tumor trials include an anti-GD2 CAR-T trial in neuroblastoma in 2004 (NCT00085930) (40) and an anti-CAIX CAR-T in renal cell carcinoma not registered on clinicaltrials.gov but published in 2006 (41). For all trials listed on clinicaltrials.gov, 32 different solid-tumor antigens have been evaluated as targets in earlyphase clinical trials. Mesothelin has been the most frequently targeted antigen in solid-tumor CAR trials $(n=22)$, followed by GD2 $(n=17)$, and EGFR $(n=16)$. Current and prospective solidtumor targets have been previously well reviewed $(42,43)$. Identification of appropriate target antigens is particularly important in solid tumors. Target antigens expressed at high density on solid tumors are often also expressed on normal tissues and are likely to result in unacceptable toxicities when attacked by CAR-T cells in vivo $(42,43)$. One approach to address this limitation focuses on tumor-specific splice variants of proteins such as EGFRvIII, which has been evaluated in 8 different trials (44). Although CARs directed at many solidtumor antigens have been evaluated and clinical responses have been observed, the clinical efficacy of these products has thus far been modest. Overall results in these trials are not comparable to the remission rates achieved in patients with B-cell malignancies (45-47).

In contrast to CARs specific for cell surface molecules, TCRbased therapies are directed against peptide epitopes presented in the context of the patient's individual HLA molecules. This approach has the advantage of targeting intracellular proteins, including unique tumor neoantigens and tumor-associated antigens that are not widely expressed on normal tissues. However, TCR specificity is HLA-restricted, and trial enrollment is therefore limited to patients (and tumors) that express specific HLA alleles. NY-ESO-1 has been the most frequent antigen targeted in TCR trials $(n=34)$, followed by MAGE ( $n=9$, Table 3A) (14). Eighty percent of TCR trials (79 of
TABLE 3A | Single targets for TCR therapies.

\begin{tabular}{lcc}
\hline Target & Number of clinical trials & Expected patient enrollment \\
\hline NY-ESO-1 & 34 & 526 \\
MAGE & 9 & 313 \\
HPV Ag & 6 & 556 \\
MART-1 & 4 & 100 \\
WT1 & 4 & 65 \\
HBV Ag & 3 & 38 \\
KRAS & 3 & 191 \\
CEA & 2 & 17 \\
CMV Ag & 2 & 19 \\
EBV Ag & 2 & 45 \\
gp100 & 2 & 24 \\
HIV Ag & 2 & 26 \\
P53 & 2 & 15 \\
AFP & 1 & 9 \\
Folate Receptor & 1 & 0 \\
HER2 & 1 & 33 \\
HERV & 1 & 24 \\
MCP Ag & 1 & 16 \\
Mesothelin & 1 & 10 \\
TGFbRII & 1 & 5 \\
TRAILxDR4 & 1 & 5 \\
\hline
\end{tabular}

TABLE 3B | Multiple targets for TCR therapies.

\begin{tabular}{lcc}
\hline Target & Number of clinical trials & Expected patient enrollment \\
\hline NY-ESO-1/LAGE-1a & 4 & 132 \\
AFP/HLA-A2 & 1 & 24 \\
HER2/CD3 & 1 & 8 \\
gp100/CD3 & 1 & 327 \\
gp100/MART-1 & 1 & 4 \\
Melan-A/MART1 & 1 & 12 \\
\hline
\end{tabular}

102) are restricted to patients who are HLA-A02 positive. HLAA11 and HLA-A24 were the next most prevalent eligible HLA alleles, included in 8 and 5 trials, respectively. Only 10 TCR studies targeted hematopoietic tumor antigens, mainly WT1 $(n=3)$ and NY-ES0-1 $(n=3)$. In December 2019, results of a phase I trial featuring a TCR specific to peptides shared by NYESO- 1 and LAGE- 1 yielded a $42 \%$ overall response rate 1-year post infusion in multiple myeloma (NCT01352286) (48). In efforts to reduce on-target off-tumor toxicities, TCRs have also been designed for cancer-specific mutations, like TGF$\beta$ receptor II polymorphisms in colorectal cancer (NCT03431311), EBV-LMP1 epitopes that are highly expressed in EBV-associated nasopharyngeal carcinoma (NCT03648697), and KRAS G12V in pancreatic cancer harboring that mutation (NCT04146298).

Though anti-CD19 and anti-BCMA CARs frequently induced disease remission, some patients relapse after initial response. The most frequent reasons for tumor relapse have been either lack of persistence of genetically-modified effector cells in vivo or loss of epitope expression by the tumor cells (49). In a phase IIa single agent anti-CD19-CAR trial in adult NHL, post-infusion biopsies showed CD19 antigen loss in $20 \%$ of nonresponding patients (NCT02030834) (15). Similarly, CD19 epitope loss occurred in $28 \%$ of pediatric patients who 
received anti-CD19 CAR-T cells $(14,50)$. This demonstration has led to a series of new clinical trials using CARs targeting 2 different surface antigens as a strategy to prevent relapse due to antigen loss.

Eighteen different dual CAR constructs that target multiple antigens simultaneously have now entered clinical trials (Table 2C). Multiantigen-specific CARs may have three or more targets but typically have two. Anti-CD19/CD22 (n=17) and anti-CD19/ CD20 ( $n=13)$ combinations were most frequently tested. Several multiantigen-specific TCRs have also been developed, mainly NY-ESO-1/LAGE-1a $(n=4)$ (Table 3B). In a different approach, two trials explored a modulable receptor using a CD16v CAR coadministered with monoclonal antibodies (mAb). By enabling generic antibody binding through CD16, this strategy allowed targeting of different diseases by interchanging commercially available mAbs like anti-CD20 (NCT02776813) and antiHER2 (NCT03680560).

\section{BOOSTING CELL SURVIVAL AND EFFICACY THROUGH ADDITIONAL GENETIC MODIFICATIONS}

Prolonged disease remission and survival are associated with immune effector cell persistence in the tumor microenvironment (51). Immune checkpoint signaling, hypoxia, and metabolic milieu of the tumor microenvironment all promote immune evasion and tumor survival (52). As summarized in Table 4 and Supplementary Table 3, numerous strategies in the last 4 years have been used to enhance functionality of CARs and TCRs in the tumor microenvironment, including: (1) resistance to exhaustion/negative regulation, (2) secretion of cytokines, and (3) enhanced tumor homing.

The most frequent approaches entailed PD-1 knockout ( $\mathrm{n}=6$ CAR, $n=1$ TCR) and genetic modification to effect local secretion of anti-PD-1 ( $n=5$ CAR, $n=2$ TCR). Five trials describing CARs with PD-L1 blockers featured constructs that rewired PD-1 extracellular domains to an internal activating domain $(n=5)$ (53). Three trials studied CARs that could locally secrete antiPD-1 and anti-CTLA-4 antibodies $(n=3)$. Other modifications included a PD-1 Fc-receptor-like fusion protein $(n=2)$, shRNA suppression of $\mathrm{PD}-1$ expression $(\mathrm{n}=1)$, activated cytoplasmic PD-1 $(n=1)$, conferring resistance to TGF- $\beta(n=1)$, and CRISPRmediated knockout of HPK1 in anti-CD19 CAR-T (NCT04037566) $(54,55)$.

Inducing local cytokine secretion was another approach found in CAR trials $(n=12)$ to modify the tumor microenvironment and enhance effector cell activity in vivo. Local cytokine secretion by activated effector cells further avoids potential toxicities of systemic cytokine infusion. More than half of these trials targeted solid tumors $(n=7)$, but no TCR trials employed this strategy. Five trials leveraged IL-15 secretion to promote expansion and survival of memory $\mathrm{T}$ cells and enhance NK-cell mediated cytotoxicity, and one trial used both IL-15 and IL-21 $(56,57)$. Two trials explored the expression of IL7/CCL19 alone, while two others tested direct expression of IL7 receptor to enhance cell survival. IL-12 secretion by CAR cells was used for local dendritic cell maturation and T-cell proliferation with or without IL-7/CCL19 (NCT03542799,

TABLE 4 | Novel genetic modifications in CAR and TCR therapies from 2016 to 2019.

\begin{tabular}{|c|c|c|c|c|}
\hline \multirow[b]{2}{*}{ RESISTANCE TO NEGATIVE REGULATION } & \multicolumn{2}{|l|}{ CAR } & \multicolumn{2}{|c|}{ TCR } \\
\hline & PD-1 knock-out & $n=6$ & PD-1 knock-out & $\mathrm{n}=1$ \\
\hline & Anti-PD-1 expression & $\mathrm{n}=5$ & Anti-PD-1 expression & $\mathrm{n}=2$ \\
\hline & Anti-PD-1 and anti-CTLA-4 expression & $n=3$ & & \\
\hline & PD-1 Fc fusion protein secreted & $\mathrm{n}=2$ & & \\
\hline & PD-1 shRNA expression & $n=1$ & & \\
\hline & Endogenous HPK1 disruption & $n=1$ & & \\
\hline \multirow[t]{6}{*}{ INTERLEUKIN EXPRESSION } & IL15 & $\mathrm{n}=5$ & & \\
\hline & IL-7 and CCL19 & $n=2$ & & \\
\hline & IL-7 receptor & $n=2$ & & \\
\hline & IL-7 and CCL19 or IL12 & $\mathrm{n}=1$ & & \\
\hline & IL-15 or both IL-15 and IL-21 & $\mathrm{n}=1$ & & \\
\hline & IL-12 & $\mathrm{n}=1$ & & \\
\hline & EGFRt & $n=13$ & & \\
\hline & EGFRt and HERt on two different CARs & $\mathrm{n}=1$ & & \\
\hline & Herpes simplex virus thymidine kinase & $\mathrm{n}=1$ & & \\
\hline & $\mathrm{RQR8}$ & $\mathrm{n}=1$ & & \\
\hline VIRUS RESISTANCE & Resistant to HIV by CCR5 modification & $\mathrm{n}=1$ & & \\
\hline IMMUNE RESISTANCE & $\beta 2 m$ and TCR disruption & $\mathrm{n}=1$ & TCR $\alpha \beta$ disruption & $\mathrm{n}=1$ \\
\hline
\end{tabular}


NCT03932565). To enhance trafficking to tumors, CARs have been engineered to express chemokine receptors in two trials: CCR4 in anti-CD30 CAR-T for cutaneous lymphoma (NCT03602157) and CXCR5 co-expressed with anti-EGFR CAR-T in non-small cell lung cancer (NCT04153799).

The ability to use CAR-T cells to target T-cell tumors has been complicated by the fact that normal $\mathrm{T}$ cells also express the same target antigens. This results in fratricide and loss of CAR-T cells during manufacturing and in vivo after infusion (58). To avoid this cross-reactivity, one trial (NCT03690011) used CRISPR-based gene editing to knockout CD7 in T cells prior to CD7-CAR transduction of CAR-T for T-cell malignancies. While that trial was the only one to employ fratricide resistance modifications, recent results of a phase I CD5 CAR-T trial in $\mathrm{r} / \mathrm{r}$ $\mathrm{T}$-cell leukemia and lymphoma showed no sign of T-cell fratricide (NCT03081910) (59).

\section{INCREASING SAFETY OF GENETICALLY- ENGINEERED CELLS}

Along with remarkable efficacy, CAR-T cell therapies have also been associated with serious toxicities directly related to rapid expansion and activation of large numbers of activated effector cells in vivo. This has led to the development of different approaches to rapidly and selectively eliminate CAR-T cells in vivo in patients with life-threatening toxicities. One approach relies on genetic modifications such as "safety switches" that induce expression of drug-targetable molecules leading to rapid elimination of modified cells. Twenty-nine trials featured this strategy; 28 were CAR therapies, of which 22 were conducted in the USA. Safety switch triggers were based predominately on already approved drugs with known, manageable adverse effects and were, to date, studied in CARs and one TCR trial (Table 4 and Supplementary Table 3). The most studied method required rimiducid, which prompts dimerization of caspase- 9 (iCasp9) to induce apoptosis ( $\mathrm{n}=13 \mathrm{CAR}, 1$ TCR). Remaining strategies were studied only in CAR trials. Another safety switch mechanism relied on forced expression of non-functional surface molecules that can be targeted by systemic administration of monoclonal antibodies, like truncated endothelial growth factor receptor (EGFRt) $(n=13,2$ allogeneic trials), a target of cetuximab-driven antibody-dependent cell-mediated cytotoxicity (60). One trial studied EGFRt and the related truncated human epidermal growth factor receptor 2 (HERt) on two different CAR constructs. Cells edited to express herpes simplex virus-1 thymidine kinase (HSV-TK) were found in one allogeneic CAR trial and could be systemically killed upon ganciclovir administration. A construct called RQR8, which combines CD34 and CD20 target epitopes, enabling both a CD34 selection to enrich edited cell populations in manufacturing and a rituximab-induced safety-switch, was found in one trial (NCT03590574) (61). Select allogeneic CAR trials are also known to employ a rituximab-targetable CD20 mimic embedded in CAR constructs, though the trial entries did not specify use of this kill switch molecule on clinicaltrials.gov
(NCT03203369, NCT03190278, NCT04142619, NCT04150497, NCT04106076, NCT03229876, NCT02746952) (62).

\section{ALTERNATE CELLS OF ORIGIN}

Prior to 2019, cells used for CAR and TCR manufacturing were typically $\mathrm{T}$ cells sourced from autologous leukapheresis products (96\% of trials). Rarely, cord blood was used as a source of allogeneic immune cells (2 CAR-NK and 1 CAR-T cell trials). The T-cell subsets infused affects CAR-T efficiency and persistence (63). Very few trial listings specify detailed information on the composition of the CAR T cell products. Central memory cells are implicated in longer persistence and survival of adoptivelytransferred immune cells and were selectively utilized in at least 4 CAR trials (64). $\gamma \delta \mathrm{T}$ cells, which can target cells in an MHCindependent manner and have been implicated in anti-tumor responses with less cytokine release and functional exhaustion than in TCR $\alpha \beta$ signaling, have been selectively utilized in allogeneic CAR trials $(n=2)(47,65,66)$. Natural Killer $(N K)$ cell CARs have also been investigated ( $n=21$ since 2016). NK cells express multiple innate $\mathrm{MHC}$-independent activating receptors (e.g. NKG2D, natural cytotoxicity receptors, and DNAM-1) that respond to commonly upregulated ligands on transformed cells (MICA, MICB, ULPB 1-6, CD112 and others). NK cells also mediate antibody-dependent cytotoxicity through expression of CD16 (67-70).

The limited lifespan of NK cells in vivo reduces their potential for long-term adverse effects such as B-cell aplasia, and NK cells are less likely to provoke GVHD than T cells in the allogeneic setting $(71,72)$. However, NK-mediated efficacy can be shortlived as these cells become functionally exhausted and senesce, requiring supportive cytokines like IL-2, IL-15, and/or IL-21 to survive beyond 2 weeks $(73,74)$. Manufacturing NK CARs can also be challenging but a recent report summarizing clinical outcomes after infusion of anti-CD19-CAR NK cells derived from umbilical cord blood demonstrated excellent results (75). In this study, anti-CD19-CAR NK cells also secreted IL-15 that prolonged persistence in vivo, and clinical responses were achieved with little systemic toxicity. These results will likely lead to many more NK-CAR trials in the next few years.

\section{COMBINING AND MODIFYING CELL ADMINISTRATION}

As an alternative approach to enhance safety and efficacy, a variety of trials combined CAR/TCR-modified cell infusion with other systemic agents or explored alternate routes of administration and infusion (Table 5 and Supplementary Table 4). Drug-based strategies to mitigate severe inflammatory events like cytokine release syndrome (CRS) and associated neurotoxicity appeared initially in the setting of anti-CD19 CAR-T therapies $(n=7$ including one CD19/CD20 dual receptor trial). Tocilizumab, which binds soluble and membrane-bound IL-6 receptor, was the earliest reported safety drug, first mentioned in 2016 and in 3 
TABLE 5 | Novel combination and administration strategies in CAR and TCR therapies from 2016 to 2019.

\begin{tabular}{|c|c|c|c|c|c|}
\hline & & CAR & & TCR & \\
\hline \multirow[t]{10}{*}{ Combination with other medicines } & SAFETY DRUGS & Tocilizumab & $\mathrm{n}=3$ & & \\
\hline & & Anakinra & $\mathrm{n}=3$ & & \\
\hline & & Defibrotide & $\mathrm{n}=1$ & & \\
\hline & EFFICACY DRUGS & Checkpoint inhibitor & $\mathrm{n}=12$ & Checkpoint inhibitor & $\mathrm{n}=9$ \\
\hline & & Interleukin-2 & $\mathrm{n}=6$ & Interleukin-2 & $\mathrm{n}=13$ \\
\hline & & Ibrutinib & $\mathrm{n}=2$ & & \\
\hline & & Inhibitor of Gamma Secretase & $\mathrm{n}=1$ & & \\
\hline & CELLS OR VIRUS & Pulsed dendritic cells & $n=1$ & Pulsed dendritic cells & $n=1$ \\
\hline & & T cell antigen presenting cells expanding CAR-T & $\mathrm{n}=1$ & TIL Expressing TGFbDNRII & $n=1$ \\
\hline & & Oncolytic virus & $\mathrm{n}=1$ & Oncolytic virus & $n=1$ \\
\hline \multirow[t]{7}{*}{ Administration } & REGIONALLY DELIVERED & Hepatic transarterial & $\mathrm{n}=8$ & & \\
\hline & & Intracerebral & $\mathrm{n}=7$ & & \\
\hline & & Intraperitoneal & $\mathrm{n}=5$ & Intraperitoneal & $n=1$ \\
\hline & & Intra-tumoral & $\mathrm{n}=3$ & Intra-tumoral & $n=1$ \\
\hline & INTERVENTION DESIGN & Combined CAR injection & $\mathrm{n}=5$ & & \\
\hline & & Split dose & $\mathrm{n}=2$ & & \\
\hline & & Sequential administration & $\mathrm{n}=1$ & & \\
\hline
\end{tabular}

trials (76). Two studies have added safety management arms to their CAR studies, investigating tocilizumab prophylaxis for CRS and neurotoxic events (NCT03467256, NCT02348216) (77). Three late 2019 trials administered anakinra, an IL-1 receptor antagonist capable of crossing the blood brain barrier (78). NCT04148430 and NCT04150913 utilized prophylactic anakinra on day 0 or 2 post CAR infusion, respectively. NCT04205838 studied anakinra following onset of neurotoxicity and CRS. Registered in early 2019, one trial administered defibrotide, an oligonucleotide with protective effects on endothelial cells, from 5 days before lymphodepletion until 7 days post-CAR infusion (NCT03954106) (79).

Drugs were also employed to mitigate negative regulation of edited cells and promote immune activity. TCR trials utilized systemic administration of checkpoint inhibitors $(n=9)$ and IL-2 $(n=13)$. Checkpoint inhibitors were the most studied in CAR settings and have been previously well reviewed $(n=12)(47,80)$. CAR trials further explored coadministration with IL-2, ibrutinib, and gamma-secretase inhibitor $(n=6,2$, and 1 , respectively). CAR and TCR cells were co-administered with pulsed dendritic cells, T-cell antigen presenting cells, tumorinfiltrating lymphocytes, and oncolytic viruses $(n=6)$. Targeted regional delivery of CARs was more widely tested than with TCRs ( $\mathrm{n}=22$ and 2, respectively). CARs were locally supplied via hepatic artery $(n=8)$, intracerebrally $(n=7)$, intraperitoneally $(n=5)$, and intratumorally $(n=3)$ (Table 5 and Supplementary Table 4). Of trials specifying intracerebral CAR delivery, study arms included intracavitary and/or intraventricular $(n=5)$, intratumoral $(n=1)$, and intracranial $(n=1)$ injections. TCRs were administered intraperitoneally $(n=1)$ and intratumorally in non-small cell lung cancer $(n=1)$ (Table 5 and Supplementary Table 4). CAR trials also studied alternate infusion methods for modified cells, including sequential ( $\mathrm{n}=1$, NCT03407859), splitdose (NCT03152435, NCT03407859), or simultaneous administration $(\mathrm{n}=8, \mathrm{NCT} 02924753$, NCT03152435, NCT03407859, NCT03497819, NCT03620058, NCT03207178, NCT03549442, NCT04194931).

\section{UNIVERSAL ALLOGENEIC CARS}

The high cost of approved autologous CAR therapies, i.e., $\$ 373,000$ USD per patient for axicabtagene ciloleucel and tisagenlecleucel for adults with lymphoma and \$475,000 USD for tisagenlecleucel for children and young adults with B-ALL, highlights the need for less expensive and more efficient manufacturing processes (81-83). Currently, autologous CAR cell production requires a lengthy production period ranging from 8 days when manufactured at local sites to $\geq 4$ weeks when produced at commercial sites. Moreover, autologous products cannot be manufactured in time for all eligible patients, particularly individuals with rapidly progressive disease or those with insufficient peripheral immune cell numbers (84, 85). To address these issues, several groups have initiated allogeneic CAR and TCR-based trials ( $n=56$ total), 50 of which employed CAR-T cells, 58\% being anti-CD19-CARs.

Donor CARs and TCR-edited cells are promising off-the-shelf therapies if the challenges of graft versus host disease (GVHD) and short-term persistence can be mitigated by HLA-matching, specific gene knock-outs, or other cell modifications to prevent immunologic recognition and elimination of allogeneic cells in the recipient. Three allogeneic CAR trials specified HLA restrictions (NCT02050347, NCT01195480, NCT04107142). One trial initiated in 2017 described CRISPR-knockout of endogenous TCR $\alpha / \beta$ and $\beta 2$-microglobulin to eliminate expression of MHC class I molecules (NCT03166878) (84). Two trials used infusion of an anti-CD52 antibody to ablate recipient lymphocytes and prevent rejection of allogeneic effector cells (NCT03939026, NCT04093596) (86). Six trials employed safety switch molecules iCasp9 $(n=3$, NCT01494103, NCT03056339, NCT03579927), EGFRt ( $\mathrm{n}=2$, NCT03114670, NCT02028455) or HSV-TK (NCT01082926) to eliminate allogeneic effector cells in the event that effector cell infusions caused severe graft versus host disease in recipients. Remaining allogeneic trials did not specify further cell modifications on clinicaltrials.gov. 
Early results from allogeneic CAR studies are encouraging, but the number of patients treated on current trials is relatively low, and as with autologous CARs there continues to be room for further optimization. A 2019 report of anti-CD19/CD123 dual allogeneic CAR administered to three relapsed/refractory acute lymphoblastic leukemia adults achieved complete responses lasting 7-11 months (NCT03125577) (87). Cord blood-derived anti-CD19 CAR-NK cells achieved a 73\% overall response in adult non-Hodgkin's Lymphoma and chronic lymphocytic leukemia patients (NCT03056339) (75). The current status and future prospects of allogeneic CARs have been extensively reviewed $(88,89)$. While long term follow-up data is emerging, larger studies will be needed to establish the role of allogeneic CARs in the treatment of patients with hematologic and nonhematologic cancers.

\section{NON-ONCOLOGY INDICATIONS AND FUTURE APPLICATIONS}

Thus far, relatively few CAR and no TCR trials have focused on non-oncology indications $(n=7)$. Four trials focused on patients with HIV, including a CAR-T construct with zinc-fingermediated CCR5 disruption to evade HIV infection (NCT03617198). CARs were also studied in patients with Neuromyelitis Optica, Lupus Erythematosus, and Myasthenia Gravis. Lessons learned from CAR trials have already been applied to SARS-CoV-2 research. One China-based CAR trial initiated in March 2020 employs dual-targeting anti-NKG2DACE2 CAR-NK cells, which secretes IL-15 superagonist for NK cell longevity and has a GM-CSF neutralizing receptor to prevent cytokine release syndrome, in COVID-19 patients (NCT04324996). Based on previous success against CARinduced cytokine storm, trials are investigating tocilizumab in the context of systemic inflammation and/or pneumonia from COVID-19 ( $\mathrm{n}>10)(90,91)$.

While not currently in trials at time of this review, there is considerable preclinical interest in regulatory T cell (Treg) CARs as alternatives to chronic immunosuppression in solid organ transplant and prevention and/or mitigation of autoimmune diseases like Type I Diabetes, inflammatory bowel disease, autoimmune hepatitis, encephalitis, and arthritis $(92,93)$. However, CAR-Treg utilization remains challenged by relatively low abundance in circulation, lack of highly efficient GMP-compliant enrichment protocols and limited stability during in vitro expansion (92).

\section{SUMMARY}

CAR and TCR therapies have birthed a promising field where initial successes for patients with unmet clinical needs have inspired further research, investment, and technological advances. The exponential growth in this field includes expansion to new and multiantigen targets, additional genetic-engineering approaches to optimize efficacy and safety, novel combination strategies, administration techniques, and exploration of different starting cell types. Late-phase studies have begun to compare anti-CD19 and anti-BCMA CAR-T therapies against current standards of care. This review of clinical trials initiated over the past 17 years demonstrates less activity in the TCR and solid tumor spaces versus CAR-T cell utilization in hematologic malignancies, though the repertoire of targeted solid tumor antigens is expanding. If CARs targeting solid tumors or for TCR-based cellular therapies can achieve similar efficacy to that seen in CARs for hematologic malignancies, dramatic increases in numbers of clinical trials and patients anticipated on these trials will certainly follow. As evident from the current distribution of early phase clinical trials, there is a great deal of international participation in the development of novel cell therapies for patients with cancer. This is truly a global effort that is supported by wellestablished pharmaceutical companies as well as large numbers of new biotech companies and academic investigators. China is beginning to play an important role and will continue be a major contributor to new clinical trials. This review did not cover the massive pre-clinical pipeline upstream of current clinical trials. Additionally, we excluded cell therapy modalities such as cytotoxic T lymphocytes, tumor-infiltrating lymphocytes, NK cells, immunomodulatory dendritic cell- or tumor-based vaccines. We anticipate that a similar review of commercially-approved cell therapy products and trials registered on clinicaltrials.gov 2 years from now will show an exponential rise in commercial cell therapy approvals and expansion of European activities in this space. Following current trends, a skew towards CARs and hematologic malignancies may continue, albeit given earlier in treatment algorithms rather than the current relapsed/refractory setting. If advances in the engineering of CARs and TCRs for solid tumors can increase the clinical efficacy of these products, clinical activity in these areas will progress rapidly and change the practice of clinical oncology forever.

\section{AUTHOR CONTRIBUTIONS}

LP generated, analyzed the database, and reviewed the manuscript. LP and AC generated figures and tables. AC wrote the manuscript. HT-N, SN, and JR reviewed the manuscript. All authors contributed to the article and approved the submitted version.

\section{ACKNOWLEDGMENTS}

We would like to acknowledge Holly Anderson for reviewing early versions of this manuscript.

\section{SUPPLEMENTARY MATERIAL}

The Supplementary Material for this article can be found online at: https://www.frontiersin.org/articles/10.3389/fimmu.2020. 608485/full\#supplementary-material 


\section{REFERENCES}

1. Rosenberg SA, Packard BS, Aebersold PM, Solomon D, Topalian SL, Toy ST, et al. Use of tumor-infiltrating lymphocytes and interleukin-2 in the immunotherapy of patients with metastatic melanoma. A preliminary report. N Engl J Med (1988) 319:1676-80. doi: 10.1056/NEJM198812223192527

2. Kuwana $Y$, Asakura Y, Utsunomiya N, Nakanishi M, Arata Y, Itoh S, et al. Expression of chimeric receptor composed of immunoglobulin-derived V regions and T-cell receptor-derived C regions. Biochem Biophys Res Commun (1987) 149:960-8. doi: 10.1016/0006-291X(87)90502-X

3. Gross G, Waks T, Eshhar Z. Expression of immunoglobulin-T-cell receptor chimeric molecules as functional receptors with antibody-type specificity. Proc Natl Acad Sci USA (1989) 86:10024-8. doi: 10.1073/pnas.86.24.10024

4. Eshhar Z, Waks T, Gross G, Schindler DG. Specific activation and targeting of cytotoxic lymphocytes through chimeric single chains consisting of antibodybinding domains and the gamma or zeta subunits of the immunoglobulin and T-cell receptors. Proc Natl Acad Sci USA (1993) 90:720-4. doi: 10.1073/ pnas.90.2.720

5. Mavilio F, Ferrari G, Rossini S, Nobili N, Bonini C, Casorati G, et al. Peripheral blood lymphocytes as target cells of retroviral vector- mediated gene transfer. Blood (1994) 83:1988-97. doi: 10.1182/blood.V83.7.1988.blood journal8371988

6. Bunnell BA, Muul LM, Donahue RE, Blaese RM, Morgan RA. High-efficiency retroviral-mediated gene transfer into human and nonhuman primate peripheral blood lymphocytes. Proc Natl Acad Sci USA (1995) 92:7739-43. doi: $10.1073 /$ pnas.92.17.7739

7. Gallardo HF, Tan C, Ory D, Sadelain M. Recombinant Retroviruses Pseudotyped With the Vesicular Stomatitis Virus G Glycoprotein Mediate Both Stable Gene Transfer and Pseudotransduction in Human Peripheral Blood Lymphocytes. Blood (1997) 90:952-7. doi: 10.1182/blood.V90.3.952

8. Krause A, Guo HF, Latouche JB, Tan C, Cheung NK, Sadelain M. Antigendependent CD28 Signaling Selectively Enhances Survival and Proliferation in Genetically Modified Activated Human Primary T Lymphocytes. J Exp Med (1998) 188:619-26. doi: 10.1084/jem.188.4.619

9. Alvarez-Vallina L, Hawkins RE. Antigen-specific targeting of CD28-mediated T cell co-stimulation using chimeric single-chain antibody variable fragmentCD28 receptors. Eur J Immunol (1996) 26:2304-9. doi: 10.1002/ eji. 1830261006

10. Finney HM, Lawson ADG, Bebbington CR, Weir ANC. Chimeric Receptors Providing Both Primary and Costimulatory Signaling in T Cells from a Single Gene Product. J Immunol (1998) 161:2791-7.

11. Eshhar Z. From the Mouse Cage to Human Therapy: A Personal Perspective of the Emergence of T-bodies/Chimeric Antigen Receptor T Cells. Hum Gene Ther (2014) 25:773-8. doi: 10.1089/hum.2014.2532

12. Sadelain M. Chimeric Antigen Receptors: A Paradigm Shift in Immunotherapy. Annu Rev Cancer Biol (2017) 1:447-66. doi: 10.1146/ annurev-cancerbio-050216-034351

13. Lim WA, June $\mathrm{CH}$. The Principles of Engineering Immune Cells to Treat Cancer. Cell (2017) 168:724-40. doi: 10.1016/j.cell.2017.01.016

14. Maude SL, Laetsch TW, Buechner J, Rives S, Boyer M, Bittencourt H, et al. Tisagenlecleucel in Children and Young Adults with B-Cell Lymphoblastic Leukemia. N Engl J Med (2018) 378:439-48. doi: 10.1056/NEJMoa1709866

15. Schuster SJ, Svoboda J, Chong EA, Nasta SD, Mato AR, Anak Ö, et al. Chimeric Antigen Receptor T Cells in Refractory B-Cell Lymphomas. N Engl J Med (2017) 377:2545-54. doi: 10.1056/NEJMoa1708566

16. Neelapu SS, Locke FL, Bartlett NL, Lekakis LJ, Miklos DB, Jacobson CA, et al. Axicabtagene Ciloleucel CAR T-Cell Therapy in Refractory Large B-Cell Lymphoma. N Engl J Med (2017) 377:2531-44. doi: 10.1056/NEJMoa1707447

17. Research, C. for B. E. KYMRIAH (tisagenlecleucel). FDA (2019). Available at: https://www.fda.gov/vaccines-blood-biologics/cellular-gene-therapyproducts/kymriah-tisagenlecleucel

18. Novartis receives European Commission approval of its CAR-T cell therapy, Kymriah $^{\circledR}$ (tisagenlecleucel) | Novartis. Available at: https://www.novartis. com/news/media-releases/novartis-receives-european-commission-approvalits-car-t-cell-therapy-kymriah-tisagenlecleucel.

19. KYMRIAH $^{\circledR}{ }^{\circledR}$ (tisagenlecleucel). Efficacy Data \& ELIANA Clinical Trial $\mid$ HCP. Available at: https://www.hcp.novartis.com/products/kymriah/acutelymphoblastic-leukemia-children/efficacy/.
20. Research, C. for B. E. YESCARTA (axicabtagene ciloleucel). FDA (2019) Available at: https://www.fda.gov/vaccines-blood-biologics/cellular-genetherapy-products/yescarta-axicabtagene-ciloleucel.

21. Research C. for B. E. TECARTUS (brexucabtagene autoleucel). FDA (2020). Available at: https://www.fda.gov/vaccines-blood-biologics/cellular-genetherapy-products/tecartus-brexucabtagene-autoleucel.

22. Zhang JY. Lost in translation? Accountability and governance of clinical stem cell research in China. Regen Med (2017) 12:647-56. doi: 10.2217/rme-2017-0035

23. Is 'Made in China 2025' a Threat to Global Trade? Council For Rel (2019) 11:1243. doi: 10.1038/s41587-019-0316-7

24. Janssen Enters Worldwide Collaboration and License Agreement with Chinese Company Legend Biotech to Develop Investigational CAR-T AntiCancer Therapy. Content Lab - U.S. Available at: https://www.jnj.com/mediacenter/press-releases/janssen-enters-worldwide-collaboration-and-licenseagreement-with-chinese-company-legend-biotech-to-developinvestigational-car-t-anti-cancer-therapy.

25. Inc, C. B. G. Cellular Biomedicine Group Enters Into Strategic Licensing and Collaboration Agreement with a Global Leader in CAR-T Cell Therapy for Patients in China. Available at: https://www.prnewswire.com/news-releases/ cellular-biomedicine-group-enters-into-strategic-licensing-andcollaboration-agreement-with-a-global-leader-in-car-t-cell-therapy-forpatients-in-china-300719774.html.

26. Announcement: Kite Pharma Acquisition | Gilead. Available at: https://www. gilead.com/news-and-press/company-statements/kite-pharma.

27. Celgene Corporation to Acquire Juno Therapeutics, Inc. - Celgene. Available at: https://www.celgene.com/newsroom/cellular-immunotherapies/celgenecorporation-to-acquire-juno-therapeutics-inc/.

28. Bristol-Myers Squibb to Acquire Celgene to Create a Premier Innovative Biopharma Company. https://news.bms.com/news/corporate-financial/2019/ Bristol-Myers-Squibb-to-Acquire-Celgene-to-Create-a-Premier-InnovativeBiopharma-Company/default.aspx.

29. Locke FL, Ghobadi A, Jacobson CA, Miklos DB, Lekakis LJ, Oluwole OO, et al. Long-term safety and activity of axicabtagene ciloleucel in refractory large Bcell lymphoma (ZUMA-1): a single-arm, multicentre, phase 1-2 trial. Lancet Oncol (2019) 20:31-42. doi: 10.1016/S1470-2045(18)30864-7

30. Jacobson CA, Hunter BD, Redd R, Rodig SJ, Chen PH, Wright $\mathrm{K}$, et al. Axicabtagene Ciloleucel in the Non-Trial Setting: Outcomes and Correlates of Response, Resistance, and Toxicity. J Clin Oncol Off J Am Soc Clin Oncol (2020) 27:3095-106. doi: 10.1200/JCO.19.02103

31. Loretta J, Nastoupil LJ, Jain MD, Feng L, Spiegel JY, Ghobadi A, Lin Y, et al. Standard-of-Care Axicabtagene Ciloleucel for Relapsed or Refractory Large BCell Lymphoma: Results From the US Lymphoma CAR T Consortium. J Clin Oncol (2020) 27:3119-28. doi: 10.1200/JCO.19.02104

32. Bader P, Soerensen J, Rettinger E, Willasch A, Kalensee F, Ansari M, et al. Single Center Real Life Experiences in the Treatment of Pediatric, Adolescent and Young Adult ALL Patients Using Commercially Available CAR-T-Cells in Germany - Susceptibility to Bridging Chemotherapy Predicts Response. Biol Blood Marrow Trans (2020) 26:S262. doi: 10.1016/j.bbmt.2019.12.426

33. Elsallab M, Levine BL, Wayne AS, Abou-El-Enein M. CAR T-cell product performance in haematological malignancies before and after marketing authorisation. Lancet Oncol (2020) 21:e104-16. doi: 10.1016/S1470-2045(19) 30729-6

34. Abramson JS, Palomba ML, Gordon LI, Lunning MA, Wang M, Arnason J, et al. Lisocabtagene maraleucel for patients with relapsed or refractory large Bcell lymphomas (TRANSCEND NHL 001): a multicentre seamless design study. Lancet (2020) 10254:839-52. doi: 10.1016/S0140-6736(20) 31366-0

35. Brudno JN, Maric I, Hartman SD, Rose JR, Wang M, Lam N, et al. T Cells Genetically Modified to Express an Anti-B-Cell Maturation Antigen Chimeric Antigen Receptor Cause Remissions of Poor-Prognosis Relapsed Multiple Myeloma. J Clin Oncol Off J Am Soc Clin Oncol (2018) 36:2267-80. doi: 10.1200/JCO.2018.77.8084

36. Zhao W-H, Liu J, Wang BY, Chen YX, Cao XM, Yang Y, et al. A phase 1, open-label study of LCAR-B38M, a chimeric antigen receptor T cell therapy directed against $\mathrm{B}$ cell maturation antigen, in patients with relapsed or refractory multiple myeloma. J Hematol Oncol J Hematol Oncol (2018) 11:141. doi: 10.1186/s13045-018-0681-6 
37. Raje N, Berdeja J, Lin Y, Siegel D, Jagannath S, Madduri D, et al. Anti-BCMA CAR T-Cell Therapy bb2121 in Relapsed or Refractory Multiple Myeloma. $N$ Engl J Med (2019) 380:1726-37. doi: 10.1056/NEJMoa1817226

38. Lam N, Trinklein ND, Buelow B, Patterson GH, Ojha N, Kochenderfer JN. Anti-BCMA chimeric antigen receptors with fully human heavy-chain-only antigen recognition domains. Nat Commun (2020) 11:283. doi: 10.1038/ s41467-019-14119-9

39. Park JR, Digiusto DL, Slovak M, Wright C, Naranjo A, Wagner J, et al. Adoptive transfer of chimeric antigen receptor re-directed cytolytic $\mathrm{T}$ lymphocyte clones in patients with neuroblastoma. Mol Ther J Am Soc Gene Ther (2007) 15:825-33. doi: 10.1038/sj.mt.6300104

40. Louis CU, Savoldo B, Dotti G, Pule M, Yvon E, Myers GD, et al. Antitumor activity and long-term fate of chimeric antigen receptor-positive $\mathrm{T}$ cells in patients with neuroblastoma. Blood (2011) 118:6050-6. doi: 10.1182/blood2011-05-354449

41. Lamers CHJ, Sleijfer S, Vulto AG, Kruit WHJ, Kliffen M, Debets R, et al. Treatment of metastatic renal cell carcinoma with autologous T-lymphocytes genetically retargeted against carbonic anhydrase IX: first clinical experience. J Clin Oncol Off J Am Soc Clin Oncol (2006) 24:e20-2. doi: 10.1200/ JCO.2006.05.9964

42. MacKay M, Afshinnekoo E, Rub J, Hassan C, Khunte M, Baskaran N, et al. The therapeutic landscape for cells engineered with chimeric antigen receptors. Nat Biotechnol (2020) 38:233-44. doi: 10.1038/s41587-019-0329-2

43. D'Aloia MM, Zizzari IG, Sacchetti B, Pierelli L, Alimandi M. CAR-T cells: the long and winding road to solid tumors. Cell Death Dis (2018) 9:282. doi: 10.1038/s41419-018-0278-6

44. Sampson JH, Archer GE, Mitchell DA, Heimberger AB, Bigner DD. Tumorspecific immunotherapy targeting the EGFRvIII mutation in patients with malignant glioma. Semin Immunol (2008) 20:267-75. doi: 10.1016/ j.smim.2008.04.001

45. Martinez M, Moon EK. CAR T Cells for Solid Tumors: New Strategies for Finding, Infiltrating, and Surviving in the Tumor Microenvironment. Front Immunol (2019) 10:128. doi: 10.3389/fimmu.2019.00128

46. Hou B, Tang Y, Li W, Zeng Q, Chang D. Efficiency of CAR-T Therapy for Treatment of Solid Tumor in Clinical Trials: A Meta-Analysis. Dis Markers (2019) 2019:3425291. doi: 10.1155/2019/3425291

47. Zhang J, Wang L. The Emerging World of TCR-T Cell Trials Against Cancer: A Systematic Review. Technol Cancer Res Treat (2019) 18:1533033819831068. doi: $10.1177 / 1533033819831068$

48. Stadtmauer EA, Faitg TH, Lowther DE, Badros AZ, Chagin K, Dengel K, et al. Long-term safety and activity of NY-ESO-1 SPEAR T cells after autologous stem cell transplant for myeloma. Blood $A d v$ (2019) 3:2022-34. doi: 10.1182/ bloodadvances.2019000194

49. Ruella M, June CH. Chimeric Antigen Receptor T cells for B Cell Neoplasms: Choose the Right CAR for You. Curr Hematol Malig Rep (2016) 11:368-84. doi: 10.1007/s11899-016-0336-z

50. June CH, O'Connor RS, Kawalekar OU, Ghassemi S, Milone MC. CAR T cell immunotherapy for human cancer. Science (2018) 359:1361-5. doi: 10.1126/ science.aar6711

51. Petersen CT, Krenciute G. Next Generation CAR T Cells for the Immunotherapy of High-Grade Glioma. Front Oncol (2019) 9:69. doi: 10.3389/fonc.2019.00069

52. Morgan MA, Schambach A. Engineering CAR-T Cells for Improved Function Against Solid Tumors. Front Immunol (2018) 9:2493. doi: 10.3389/ fimmu.2018.02493

53. TriTE Technology. Available at: http://www.timmune.com/services/show. php?lang=en\&id $=169$.

54. Hong M, Clubb JD, Chen YY. Engineering CAR-T Cells for Next-Generation Cancer Therapy. Cancer Cell (2020). doi: 10.1016/j.ccell.2020.07.005

55. Bartolo VD, Montagne B, Salek M, Jungwirth B, Carrette F, Fourtane J, et al. A novel pathway down-modulating $\mathrm{T}$ cell activation involves HPK-1-dependent recruitment of 14-3-3 proteins on SLP-76. J Exp Med (2007) 204:681-91. doi: 10.1084/jem.20062066

56. Shum T, Kruse RL, Rooney CM. Strategies for enhancing adoptive T-cell immunotherapy against solid tumors using engineered cytokine signaling and other modalities. Expert Opin Biol Ther (2018) 18:653-64. doi: 10.1080/ 14712598.2018.1473368

57. Committing CAR T cells to memory. Sci Trans Med. https://stm.sciencemag. org/content/8/370/370ec205. doi: 10.1126/scitranslmed.aal3704
58. Cooper ML, Choi J, Staser K, Ritchey JK, Devenport JM, Eckardt K, et al. An 'off-the-shelf' fratricide-resistant CAR- T for the treatment of $\mathrm{T}$ cell hematologic malignancies. Leukemia (2018) 32:1970-83. doi: 10.1038/ s41375-018-0065-5

59. Hill LC, Rouce R, Smith T, Yang L, Srinivasan M, Zhang H, et al. Safety and Anti-Tumor Activity of CD5 CAR T-Cells in Patients with Relapsed/ Refractory T-Cell Malignancies. Blood (2019) 134:199-9. doi: 10.1182/ blood-2019-129559

60. García-Foncillas J, Sunakawa Y, Aderka D, Wainberg Z, Ronga P, Witzler P, et al. Distinguishing Features of Cetuximab and Panitumumab in Colorectal Cancer and Other Solid Tumors. Front Oncol (2019) 9:849. doi: 10.3389/ fonc. 2019.00849

61. Philip B, Kokalaki E, Mekkaoui L, Thomas S, Straathof K, Flutter B, et al. A highly compact epitope-based marker/suicide gene for easier and safer T-cell therapy. Blood (2014) 124:1277-87. doi: 10.1182/blood-2014-01-545020

62. McLellan AD, Ali Hosseini Rad SM. Chimeric Antigen Receptor T Cell Persistence and Memory Cell Formation. Immunol Cell Biol (2019) 97(7):66474. doi: $10.1111 /$ imcb. 12254

63. Knochelmann HM, Smith AS, Dwyer CJ, Wyatt MM, Mehrotra S, Paulos CM. CAR T Cells in Solid Tumors: Blueprints for Building Effective Therapies. Front Immunol (2018) 9:1740. doi: 10.3389/fimmu.2018.01740

64. McLellan AD, Ali Hosseini Rad SM. Chimeric antigen receptor T cell persistence and memory cell formation. Immunol Cell Biol (2019) 97:66474. doi: $10.1111 /$ imcb. 12254

65. Yazdanifar M, Barbarito G, Bertaina A, Airoldi I. $\gamma \delta$ T Cells: The Ideal Tool for Cancer Immunotherapy. Cells (2020) 9:1305. doi: 10.3390/cells9051305

66. Xu Y, Yang Z, Horan LH, Zhang P, Liu L, Zimdahl B, et al. A novel antibodyTCR (AbTCR) platform combines Fab-based antigen recognition with gamma/delta-TCR signaling to facilitate T-cell cytotoxicity with low cytokine release. Cell Discovery (2018) 4:62. doi: 10.1038/s41421-018-0066-6

67. Xie G, Dong H, Liang Y, Ham JD, Romee R, Chen J. CAR-NK cells: A promising cellular immunotherapy for cancer. EBioMedicine (2020) 59:102975. doi: 10.1016/j.ebiom.2020.102975

68. Sayitoglu EC, Georgoudaki A, Chrobok M, Ozkazanc D, Josey BJ, Arif M, et al. Boosting Natural Killer Cell-Mediated Targeting of Sarcoma Through DNAM-1 and NKG2D. Front Immunol (2020) 11:40. doi: 10.3389/ fimmu.2020.00040

69. Pende D, Falco M, Vitale M, Cantoni C, Vitale C, Munari E, et al. Killer IgLike Receptors (KIRs): Their Role in NK Cell Modulation and Developments Leading to Their Clinical Exploitation. Front Immunol (2019) 10:1179. doi: 10.3389/fimmu.2019.01179

70. Natural killer cells for cancer immunotherapy: a new CAR is catching up. EBioMedicine (2019) 39:1-2. doi: 10.1016/j.ebiom.2019.01.018

71. Mehta RS, Rezvani K. Chimeric Antigen Receptor Expressing Natural Killer Cells for the Immunotherapy of Cancer. Front Immunol (2018) 9:283. doi: 10.3389/fimmu.2018.00283

72. Simonetta F, Alvarez M, Negrin RS. Natural Killer Cells in Graft-versus-HostDisease after Allogeneic Hematopoietic Cell Transplantation. Front Immunol (2017) 8:465. doi: 10.3389/fimmu.2017.00465

73. Seo H, Jeon I, Kim B, Park M, Bae E, Song B, et al. IL-21-mediated reversal of NK cell exhaustion facilitates anti-tumour immunity in MHC class I-deficient tumours. Nat Commun (2017) 8:15776. doi: 10.1038/ncomms15776

74. Judge SJ, Murphy WJ, Canter RJ. Characterizing the Dysfunctional NK Cell: Assessing the Clinical Relevance of Exhaustion, Anergy, and Senescence. Front Cell Infect Microbiol (2020) 10:49. doi: 10.3389/fcimb.2020.00049

75. Liu E, Marin D, Banerjee P, Macapinlac HA, Thompson P, Basar R, et al. Use of CAR-Transduced Natural Killer Cells in CD19-Positive Lymphoid Tumors. N Engl J Med (2020) 382:545-53. doi: 10.1056/NEJMoa1910607

76. Guaraldi G, Meschiari M, Cozzi-Lepri A, Milic J, Tonelli R, Menozzi M, et al. Tocilizumab in patients with severe COVID-19: a retrospective cohort study. Lancet Rheumatol (2020) 2:e474-84. doi: 10.1016/S2665-9913(20)30173-9

77. Locke F, Neelapu S, Bartlett N, Lekakis L, Jacobson C, Braunschweig I, et al. Preliminary Results of Prophylactic Tocilizumab After Axicabtagene Ciloleucel (axi-cel; KTE-C19) Treatment for Patients with Relapsed/ Refractory, Aggressive NHL. Blood (2017) 130:1547. doi: 10.1182/ BLOOD.V130.SUPPL_1.1547.1547

78. Mehta P, Cron RQ, Hartwell J, Manson JJ, Tattersall RS. Silencing the cytokine storm: the use of intravenous anakinra in haemophagocytic 
lymphohistiocytosis or macrophage activation syndrome. Lancet Rheumatol (2020) 2:e358-67. doi: 10.1016/S2665-9913(20)30096-5

79. Stein C, Castanotto D, Krishnan A, Nikolaenko L. Defibrotide (Defitelio): A New Addition to the Stockpile of Food and Drug Administration-approved Oligonucleotide Drugs. Mol Ther Nucleic Acids (2016) 5:e346. doi: 10.1038/ mtna.2016.42

80. Yoon DH, Osborn MJ, Tolar J, Kim CJ. Incorporation of Immune Checkpoint Blockade into Chimeric Antigen Receptor T Cells (CAR-Ts): Combination or Built-In CAR-T. Int J Mol Sci (2018) 19:340. doi: 10.3390/ijms19020340

81. Novartis could cut its Kymriah price to $\$ 160,000$ and keep its profit margins: study. FiercePharma. https://www.fiercepharma.com/pharma/group-saysnovartis-kymriah-should-cost-160-000.

82. Bach PB, Giralt SA, Saltz LB. FDA Approval of Tisagenlecleucel: Promise and Complexities of a $\$ 475000$ Cancer Drug. JAMA (2017) 19:1861-2. doi: 10.1001/jama.2017.15218

83. Bach PB, Giralt SA, Saltz LB. FDA Approval of Tisagenlecleucel: Promise and Complexities of a $\$ 475000$ Cancer Drug. JAMA (2017) 318:1861-2. doi: 10.1001/jama.2017.15218

84. Zhao J, Lin Q, Song Y, Liu D. Universal CARs, universal T cells, and universal CAR T cells. J Hematol Oncol J Hematol Oncol (2018) 11:132. doi: 10.1186/ s13045-018-0677-2

85. Boyiadzis MM, Dhodapkar MV, Brentjens RJ, Kochenderfer JN, Neelapu SS, Maus MV, et al. Chimeric antigen receptor (CAR) T therapies for the treatment of hematologic malignancies: clinical perspective and significance. J Immunother Cancer (2018) 6(1):137. doi: 10.1186/s40425-018-0460-5

86. Graham C, Jozwik A, Pepper A, Benjamin R. Allogeneic CAR-T Cells: More than Ease of Access? Cells (2018) 7:155. doi: 10.3390/cells7100155

87. Tu S, Deng L, Huang R, Zhou X, Yang J, Zhou W, et al. A Novel Chimeric Antigen Receptor T Cells Therapy Strategy That Dual Targeting CD19 and CD123 to Treat Relapsed Acute Lymphoblastic Leukemia after Allogeneic Hematopoietic Stem Cell Transplantation. Blood (2018) 132:4015-5. doi: 10.1182/blood-2018-99-118526
88. Zhao J, Song Y, Liu D. Clinical trials of dual-target CAR T cells, donorderived CAR T cells, and universal CAR $\mathrm{T}$ cells for acute lymphoid leukemia. J Hematol Oncol J Hematol Oncol (2019) 12:17. doi: 10.1186/ s13045-019-0705-x

89. Depil S, Duchateau P, Grupp SA, Mufti G, Poirot L. 'Off-the-shelf' allogeneic CAR T cells: development and challenges. Nat Rev Drug Discovery (2020) 19:185-99. doi: 10.1038/s41573-019-0051-2

90. Luo P, Liu Y, Qiu L, Liu X, Liu D, Li J, et al. Tocilizumab treatment in COVID19: A single center experience. J Med Virol (2020) 92:814-8. doi: 10.1002/ jmv. 25801

91. Biran N, Ip A, Ahn J, Go RC, Wang S, Mathura S, et al. Tocilizumab among patients with COVID-19 in the intensive care unit: a multicentre observational study. Lancet Rheumatol (2020) 10:e603-12. doi: 10.1016/ S2665-9913(20)30277-0

92. Fritsche E, Volk H-D, Reinke P, Abou-El-Enein M. Toward an Optimized Process for Clinical Manufacturing of CAR-Treg Cell Therapy. Trends Biotechnol (2020) 1099-112. doi: 10.1016/j.tibtech.2019.12.009

93. Romano M, Fanelli G, Albany CJ, Giganti G, Lombardi G. Past, Present, and Future of Regulatory T Cell Therapy in Transplantation and Autoimmunity. Front Immunol (2019) 10. doi: 10.3389/fimmu.2019.00043

Conflict of Interest: The authors declare that the research was conducted in the absence of any commercial or financial relationships that could be construed as a potential conflict of interest.

Copyright (๑) 2021 Pinte, Cunningham, Trébéden-Negre, Nikiforow and Ritz. This is an open-access article distributed under the terms of the Creative Commons Attribution License (CC BY). The use, distribution or reproduction in other forums is permitted, provided the original author(s) and the copyright owner(s) are credited and that the original publication in this journal is cited, in accordance with accepted academic practice. No use, distribution or reproduction is permitted which does not comply with these terms. 